\title{
CARACTERÍSTICAS FÍSICO-gUÍMICAS DE ACEROLA DO BANCO ATIVO DE GERMOPLASMA EM PERNAMBUCO ${ }^{1}$
}

\author{
Rosimar dos Santos MUSSER ${ }^{2, *}$, Margarida Agostinho LEMOS², Vera Lúcia Arroxelas Galvão de LIMA², \\ Enayde de Almeida MÉLO³, Ildo Eliezer LEDERMAN", Venézio Felipe dos SANTOS ${ }^{4}$
}

\section{RESUMO}

As características físico-químicas de acerolas maduras, provenientes de 12 genótipos, cultivados no Banco Ativo de Germoplasma da Universidade Federal Rural de Pernambuco (UFRPE), colhidas no inverno/1999, verão/2000 e verão/2001 foram avaliadas. A análise conjunta das três safras revelou as seguintes variações médias: ácido ascórbico de 1067 a $1846 \mathrm{mg} / 100 \mathrm{~g}$ de polpa; antocianinas totais de 3,8 a 47,4mg/100g de polpa; flavonóis totais de 7,0 a 18,5mg de quercetina/100g de polpa; acidez total titulável (ATT) de 1,04 a 1,87g de ácido málico/100g de polpa; sólidos solúveis totais (SST) de 7,0 e 8,4 ${ }^{\circ}$ Brix; relação SST/ATT de 4,4 a 6,9 e pH de 3,11 e 3,41. Levando em consideração as características avaliadas, todos os genótipos, exceto o 015-CPA que apresentou teor de ácido ascórbico inferior ao exigido pelas indústrias de transformação, são potencialmente promissores.

Palavras-chave: Malpighia emarginata D.C.; genótipos; fitoquímicos; qualidade de frutos.

\section{SUMMARY}

THE PHYSICOCHEMICAL CHARACTERISTICS OF ACEROLA FRUITS FROM GERMOPLASM ACTIVE BANK IN PERNAMBUCO. Physicochemical characteristics of mature acerola fruits from 12 genotypes cultivated at Active Germoplasm Bank of Universidade Federal Rural de Pernambuco (UFRPE), harvested at winter/1999, summer/2000 and summer/2001, were analyzed. The joint analysis of these fruits showed the following average variation: ascorbic acid 1067 to $1846 \mathrm{mg} / 100 \mathrm{~g}$ of fruit pulp; total anthocyanins 3.8 to $47.4 \mathrm{mg} / 100 \mathrm{~g}$ of fruit pulp; total flavonols 7.0 to 18.5 quercetin $\mathrm{mg} / 100 \mathrm{~g}$ of fruit pulp; titratable acidity (TA) 1.04 to $1.87 \mathrm{~g}$ of malic acid/ $100 \mathrm{~g}$ of fruit pulp; total soluble solids (TSS) 7.0 to $8.4^{\circ} \mathrm{Brix}$; TSS/TA ratio 4.4 to 6.9 and $\mathrm{pH} 3.11$ to 3.41 . Considering the characteristics analyzed, all genotypes, except 015-CPA, which showed ascorbic acid level lower than the transformation industry standard, are potentially promising.

Keywords: Malpighia emarginata D.C.; genotypes; phytochemicals; fruits quality.

\section{1 - INTRODUÇÃO}

As características físico-químicas da acerola em diferentes estádios de maturação têm sido bastante estudadas, especialmente no que se refere ao teor de ácido ascórbico. A acerola destaca-se dentre os frutos tropicais por apresentar elevada quantidade deste constituinte [19, 25]. O teor de ácido ascórbico, parâmetro básico utilizado na seleção de aceroleiras, bem como o de acidez total titulável (ATT), de sólidos solúveis totais (SST) e pH, são influenciados pela localização geográfica, estádio de maturação do fruto, época de colheita e tratos culturais além dos fatores genéticos [20, 24]. O teor de ácido ascórbico também é utilizado como parâmetro pelas indústrias de transformação, as quais estabelecem para esse fruto o teor mínimo de 1200mg de ácido ascórbico/100g de polpa [16].

Nas condições edafoclimáticas brasileiras, acerolas apresentam valores de SST que variam de 5- $12^{\circ} \mathrm{Brix}$, com média em torno de $7-8^{\circ}$ Brix $[3,13,24]$. A relação

\footnotetext{
1. Recebido para publicação em 06/01/2003. Aceito para publicação em 02/09/2004 (001037). Parte da Tese da primeira autora apresentada ao Programa de Pós-Graduação em Botânica/ Universidade Federal Rural de Pernambuco executada com apoio da PPGB/UFRPE.

2. Departamento de Agronomia/UFRPE, Av. Dom Manoel de Medeiros s/n, CEP: 52171-900, PE, E-mail: rmusser@ufrpe.br

3. Departamento de Ciências Domésticas/UFRPE

4. Instituto de Pesquisa Agropecuária do Estado de Pernambuco (IPA), Caixa Postal: 1022, Recife, PE

* A quem a correspondência deve ser enviada.
}

SST/ATT é um importante atributo de qualidade em acerolas, forma usual para avaliar o sabor e selecionar a matéria-prima para processamento. Esta relação aumenta em função da maturação do fruto, como resultado da elevação dos SST [23].

A cor vermelha da acerola é decorrente da presença de antocianinas [10]. Em função da variabilidade genética essa coloração pode apresentar várias tonalidades. LIMA et al. [18] estudando seleções de acerola constataram uma variação no teor de antocianinas totais de 14,06 a 50,98mg/100g de polpa. Nestas seleções foi, também, observada a existência de frutos com película de coloração vermelha e polpa alaranjada. A EMBRAPA, com base em seu Banco Ativo de Germoplasma de acerola, definiu a relação de descritores mínimos, onde consta a cor vermelha como descritor da coloração da polpa do fruto maduro, e o teor total de antocianinas como um dos dados químicos da polpa [21]. Os flavonóis, pigmentos responsáveis pela cor branca ou amarela clara, sempre acompanham as antocianinas em frutos, provavelmente porque apresentam rotas de biossíntese semelhantes, sendo importante por atuarem na co-pigmentação das antocianinas [14].

Com o intuito de selecionar aceroleiras de interesse agronômico, para a Zona da Mata de Pernambuco, como copa produtora, a UFRPE instalou, em Carpina/PE, um Banco Ativo de Germoplasma. Considerando a variabilidade dos parâmetros físico-químicos em acerolas, este trabalho teve por objetivo caracterizar frutos maduros de 12 genótipos deste Banco, com vistas a selecionar aqueles de interesse industrial. 


\section{2 - MATERIAL E MÉTODOS}

Na Estação Experimental de Cana-de-Açúcar do Carpina (E.E.C.A.C./UFRPE), municipio de Carpina/PE; latitude $7^{\circ} 51^{\prime} 04$ ", longitude $35^{\circ} 14^{\prime} 27^{\prime \prime} \mathrm{w}$, a $178 \mathrm{~m}$ de altitude, onde predomina o tipo climático "AS" tropical chuvoso com verão seco, segundo a classificação de Köppen, encontra-se instalado o Banco Ativo de Germoplasma (BAG) de aceroleiras implantado em junho de 1998. No verão/2000 (fevereiro) foi introduzida ao sistema de produção a irrigação por microaspersão. Os dados de temperatura, insolação e precipitação estão apresentados nas Figuras 1, 2 e 3. Dos genótipos, foram escolhidos 12, por terem sido os primeiros implantados no BAG, para avaliar as características físicoquímicas dos frutos. No período mínimo de seis meses, coincidindo com a estação úmida (inverno-agosto-setembro/1999) e seca (verão-fevereiro/2000 e março/ 2001), frutos maduros foram coletados e imediatamente congelados em freezer $\left(-18^{\circ} \mathrm{C}\right)$ no Laboratório da E.E.C.A.C. Posteriormente, foram acondicionados em caixa isotérmica e transportados ao Laboratório de Análises Físico-Químicas e Sensorial de Alimentos do Departamento de Ciências Domésticas/UFRPE. Os frutos foram processados em centrífuga doméstica, e as polpas obtidas, utilizadas para as análises físico-químicas, que foram realizadas num prazo máximo de sete dias após a colheita.

O teor de ácido ascórbico foi quantificado pelo método titulométrico, utilizando 2,6 diclorofenol indofenol [4], modificado por BEZERRA NETO, ANDRADE \& BARRETO [7] que utilizaram solução de ácido oxálico, como solvente, em substituição ao ácido metafosfórico. As determinações de acidez total titulável (ATT), sólidos solúveis totais (SST) e pH foram efetuadas utilizando os métodos descritos nas normas analíticas do INSTITUTO ADOLFO LUTZ [15].

Para a determinação de antocianinas e flavonóis totais, as polpas foram homogeneizadas com solução extratora (etanol 95\%: $\mathrm{HCl}$ 1,5N) (85: $15 \mathrm{v} / \mathrm{v})$ e estocadas por $12 \mathrm{~h} \mathrm{a} 4^{\circ} \mathrm{C}$. Em seguida, foram filtradas e os resíduos lavados exaustivamente com a solução extratora até a completa remoção dos pigmentos. Os filtrados foram coletados em balões volumétricos de $100 \mathrm{~mL}$, aferidos com a solução extratora, deixados em repouso, sob o abrigo da luz, por $2 \mathrm{~h}$ a temperatura ambiente. A leitura espectrofotométrica foi efetuada a $535 \mathrm{~nm}$ e $374 \mathrm{~nm}$ para a quantificação de antocianinas e flavonóis totais, respectivamente [17].

O delineamento experimental foi em blocos completos casualizados (cinco blocos), com doze tratamentos (doze genótipos) tendo uma planta por parcela, em espaçamento $5 \times 4 \mathrm{~m}$ totalizando 60 plantas. Periodicamente, foram realizados tratos culturais (capinas, adubações, controle fitossanitário, podas de limpeza e irrigação). Para a avaliação estatística, os resultados das análises dos frutos da safra de 1999 foram submetidos ao programa NTIA (versão 4.2.1 - Universidade Federal de Viçosa), e os dos frutos das demais safras ao programa GENES (versão 1.0 - EMBRAPA), sendo as mé- dias comparadas pelo teste "SNK" (Student-NewmanKeuls) ao nível de $5 \%$ de probabilidade.

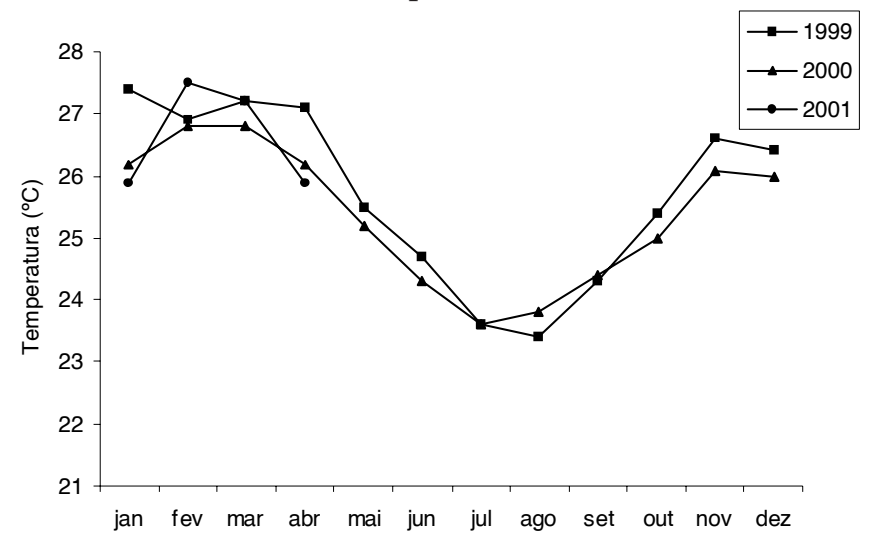

FIGURA 1. Variação média anual da temperatura no município de Carpina/PE.

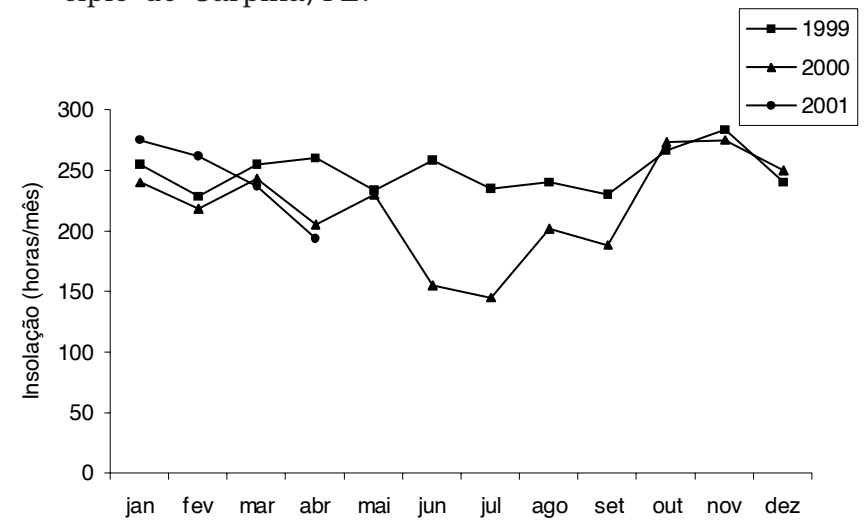

FIGURA 2. Variação média anual da insolação (horas/mês) no município de Carpina/PE.

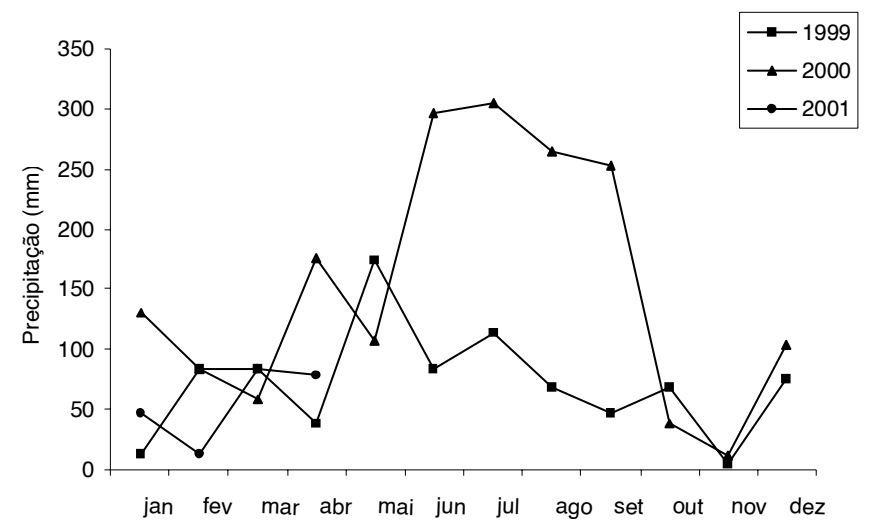

FIGURA 3. Variação média anual da pluviosidade (mm) no município de Carpina/PE.

\section{3 - RESULTADOS E DISCUSSÃO}

\section{1 - Ácido ascórbico}

A análise conjunta das safras (média das safras) demonstrou haver variações nos teores de ácido ascórbico entre os genótipos (Tabela 1). Os frutos da safra inverno/1999, coletados em agosto/setembro, meses de 
menor pluviosidade (Figura 3), apresentaram a maior amplitude de variação e os maiores níveis de ácido ascórbico sem, contudo, haver diferença estatística significativa $(\mathrm{P}>0,05)$ entre os genótipos. Estes teores variaram de 1405 a 2293mg de ácido ascórbico/100g de polpa, os quais estão próximos aos encontrados por ALVES [1], GONZAGA NETO, MATTUZ \& SANTOS [13] e GOMES et al. [12].

TABELA 1. Teor de ácido ascórbico (mg/100g) em acerolas maduras do Banco Ativo de Germoplasma, Carpina/PE.

\begin{tabular}{|c|c|c|c|c|}
\hline \multirow{2}{*}{$\begin{array}{l}\text { Genótipos } \\
\text { (códigos) }\end{array}$} & \multicolumn{4}{|c|}{ Safras } \\
\hline & Inverno/1999 & Verão/2000 & Verão/2001 & Média \\
\hline 002-SPE & $1798 \pm 135^{* a}$ & $1094 \pm 95^{\mathrm{bcd}}$ & $1279 \pm 147^{\mathrm{abc}}$ & $1398 \pm 108^{\mathrm{bC}}$ \\
\hline 003-APE & $1488 \pm 73^{a}$ & $955 \pm 55^{\mathrm{cd}}$ & $1370 \pm 176^{a b c}$ & $1217 \pm 99^{c}$ \\
\hline 004-RPE & $2293 \pm 376^{a}$ & $1618 \pm 71^{a}$ & $1715 \pm 135^{a}$ & $1846 \pm 135^{a}$ \\
\hline 005-APE & $2045 \pm 8^{a}$ & $1507 \pm 150^{\mathrm{ab}}$ & $1616 \pm 99^{a}$ & $1642 \pm 90^{\mathrm{ab}}$ \\
\hline 006-TPA & $1771 \pm 248^{a}$ & $1009 \pm 46^{\mathrm{cd}}$ & $1269 \pm 94^{\mathrm{abc}}$ & $1320 \pm 112^{b c}$ \\
\hline 007-TPA & $2181 \pm 115^{a}$ & $1196 \pm 85^{\mathrm{abcd}}$ & $1521 \pm 72^{\mathrm{a}}$ & $1594 \pm 119^{a b}$ \\
\hline 008-СРА & $1660 \pm 185^{a}$ & $1191 \pm 182^{\mathrm{abcd}}$ & $1007 \pm 40^{\mathrm{bc}}$ & $1247 \pm 112^{c}$ \\
\hline 011-BPA & $1909 \pm 261^{a}$ & $1275 \pm 76^{\mathrm{abcd}}$ & $964 \pm 77^{c}$ & $1345 \pm 130^{b c}$ \\
\hline 012-СРА & $1926 \pm 159^{a}$ & $1344 \pm 105^{a b c}$ & $1446 \pm 156^{a b}$ & $1572 \pm 102^{a b}$ \\
\hline 013-СРА & $2068 \pm 74^{a}$ & $1346 \pm 135^{\mathrm{abc}}$ & $1316 \pm 109^{a b c}$ & $1595 \pm 114^{a b}$ \\
\hline 014-СРА & $1686 \pm 143^{a}$ & $1074 \pm 42^{b c d}$ & $1295 \pm 64^{a b c}$ & $1328 \pm 81^{b c}$ \\
\hline 015-СРA & $1405 \pm 182^{a}$ & $824 \pm 45^{d}$ & $1039 \pm 85^{b c}$ & $1067 \pm 86^{c}$ \\
\hline Média & 1869 & 1203 & 1326 & 1434 \\
\hline L. sup. ${ }^{1}$ & 2032 & 1349 & 1477 & 1573 \\
\hline L. inf. ${ }^{1}$ & 1707 & 1057 & 1174 & 1295 \\
\hline C.V. $(\%)^{2}$ & 20 & 19 & 16 & 22 \\
\hline
\end{tabular}

* Médias seguidas da mesma letra na coluna não diferem significativamente ao nível de $5 \%$ de probabilidade pelo teste de Student-Newman-Keuls (SNK).

${ }^{1}$ Intervalo de confiança da média com $95 \%$ de probabilidade, limites superior e

Coeficiente de variação.

Na safra verão/2000, os maiores teores de ácido ascórbico foram detectados nos frutos do genótipo 004-RPE quando comparados aos genótipos 002-SPE, 003-APE, 006-TPA, 014-CPA e 015-CPA $(\mathrm{P}<0,05)$. Em função da elevada temperatura e luminosidade do período (Figuras 1 e 2), esperava-se que os teores de ácido ascórbico, em todos os genótipos, fossem mais elevados do que aqueles da safra inverno/1999, fato que não ocorreu. A introdução da irrigação no manejo pode justificar a redução dos teores desta vitamina nos frutos dessa safra. Em decorrência da redução dos teores deste constituinte, um maior controle da irrigação, através de menor fornecimento da quantidade de água, foi efetuado, principalmente, durante a frutificação. Desta forma, ficou evidenciada a importância do manejo da irrigação nesta cultura, por interferir diretamente nos niveis de ácido ascórbico. No que se refere à safra 2001, dentre os genótipos que apresentaram o maior teor de ácido ascórbico, destaca-se novamente o genótipo 004-RPE.

Os níveis médios de ácido ascórbico encontrados situaram-se dentro da faixa descrita para frutos maduros da cultivar Sertaneja [11] e, superaram os teores das demais cultivares lançadas no Brasil [8, 9]. A maioria dos genótipos, exceto o 015-CPA, mostraram na análise conjunta das três safras, níveis de ácido ascórbico acima de $1200 \mathrm{mg} / 100 \mathrm{~g}$ de polpa, padrão mínimo exigi- do pelas indústrias [16]. Constata-se, portanto, que o teor de ácido ascórbico apresentou variação entre os genótipos, bem como nos frutos de cada genótipo ao longo das safras. O conhecimento dos recursos genéticos existentes em um banco de germoplasma e a adoção de manejo adequado da irrigação permitem selecionar plantas com elevados teores de ácido ascórbico.

\section{2 - Acidez total titulável (ATT)}

A acidez dos frutos de acerola expressa em ácido málico, encontra-se apresentada na Tabela 2. Na safra inverno/ 1999 foi detectada uma variação de 1,31 a 2,04g de ácido málico/100g de polpa. Os genótipos 004-RPE, 005-APE, 007-TPA, 008-CPA e 013-CPA foram superiores, estatisticamente $(\mathrm{P}<0,05)$, ao genótipo 015-CPA, porém não diferindo dos demais.

TABELA 2. Teor de acidez total titulável (g de ácido málico/ $100 \mathrm{~g})$ em acerolas maduras do Banco Ativo de Germoplasma, Carpina/PE.

\begin{tabular}{|c|c|c|c|c|}
\hline \multirow{2}{*}{$\begin{array}{l}\text { Genótipos } \\
\text { (códigos) }\end{array}$} & \multicolumn{4}{|c|}{ Safras } \\
\hline & Inverno/1999 & Verão/2000 & Verão/2001 & Média \\
\hline 002-SPE & $1,68 \pm 0,05^{\text {* alo }}$ & $1,18 \pm 0,04^{D C C}$ & $1,45 \pm 0,19^{\mathrm{DCO}}$ & $1,44 \pm 0,08^{\mathrm{cd}}$ \\
\hline 003-APE & $1,56 \pm 0,05^{a b}$ & $0,98 \pm 0,04^{c d}$ & $1,45 \pm 0,10^{\text {bcd }}$ & $1,27 \pm 0,09^{d}$ \\
\hline 004-RPE & $2,04 \pm 0,15^{a}$ & $1,67 \pm 0,05^{a}$ & $1,94 \pm 0,12^{a}$ & $1,87 \pm 0,07^{a}$ \\
\hline 005-APE & $1,95 \pm 0,06^{a}$ & $1,56 \pm 0,07^{a}$ & $1,65 \pm 0,05^{b}$ & $1,67 \pm 0,05^{b}$ \\
\hline 006-TPA & $1,81 \pm 0,15^{a b}$ & $1,12 \pm 0,07^{b c}$ & $1,36 \pm 0,05^{\text {bcde }}$ & $1,40 \pm 0,09^{c d}$ \\
\hline 007-TPA & $1,93 \pm 0,05^{a}$ & $1,27 \pm 0,03^{b}$ & $1,63 \pm 0,08^{b c}$ & $1,59 \pm 0,08^{b c}$ \\
\hline 008-CPA & $2,01 \pm 0,13^{a}$ & $1,27 \pm 0,08^{b}$ & $1,37 \pm 0,11^{\text {bcde }}$ & $1,49 \pm 0,11^{\text {bcd }}$ \\
\hline 011-BPA & $1,73 \pm 0,17^{a b}$ & $1,12 \pm 0,05^{b c}$ & $1,18 \pm 0,10^{d e}$ & $1,32 \pm 0,09^{d}$ \\
\hline 012-CPA & $1,54 \pm 0,11^{a b}$ & $1,27 \pm 0,04^{b}$ & $1,38 \pm 0,13^{\text {bcde }}$ & $1,40 \pm 0,06^{c d}$ \\
\hline 013-СРA & $1,92 \pm 0,07^{a}$ & $1,34 \pm 0,07^{b}$ & $1,45 \pm 0,10^{\mathrm{bcd}}$ & $1,58 \pm 0,08^{b c}$ \\
\hline 014-СРA & $1,48 \pm 0,12^{a b}$ & $1,21 \pm 0,05^{b c}$ & $1,25 \pm 0,08^{\text {cde }}$ & $1,30 \pm 0,06^{d}$ \\
\hline 015-СРA & $1,31 \pm 0,15^{b}$ & $0,85 \pm 0,04^{d}$ & $1,03 \pm 0,05^{e}$ & $1,04 \pm 0,07^{e}$ \\
\hline Média & 1,74 & 1,24 & 1,43 & 1,45 \\
\hline L. sup. ${ }^{1}$ & 1,89 & 1,38 & 1,59 & 1,58 \\
\hline L. inf. ${ }^{1}$ & 1,59 & 1,09 & 1,28 & 1,31 \\
\hline C.V. $(\%)^{2}$ & 13,28 & 10,54 & 12,93 & 14,72 \\
\hline
\end{tabular}

* Médias seguidas da mesma letra na coluna não diferem significativamente ao nível de $5 \%$ de probabilidade pelo teste de Student-Newman-Keuls (SNK). inferior. ${ }_{2}^{2}$ Coeficiente de variação.

Na safra verão/2000 e verão/2001, a acidez dos frutos variou de 0,85 a 1,67g e de 1,03 a 1,94g de ácido málico/100g de polpa, respectivamente, evidenciando que o controle da irrigação, realizado no ano de 2001, contribuiu para elevação desse parâmetro. A predominância dos mesmos intervalos de confiança da média evidencia uma tendência de forte associação fenotípica entre a acidez e o ácido ascórbico em todas as safras avaliadas. A análise conjunta das safras (média das safras), em relação à acidez, indica o genótipo 004-RPE como superior estatisticamente $(\mathrm{P}<0,05)$.

\section{3 - Sólidos solúveis totais (SST)}

Na safra inverno/1999 (Tabela 3), os valores de SST (7,7 a $10,8^{\circ}$ Brix) não apresentaram diferença estatística $(\mathrm{P}>0,05)$ entre os genótipos, enquanto que na safra verão/2000 os teores variaram de 5,8 a $7,3^{\circ}$ Brix. Nos genó- 
tipos 004-RPE, 005-APE, 006-TPA e 007-TPA, os teores de SST foram superiores aos do genótipo 015-CPA sem, contudo, diferirem estatisticamente dos demais $(\mathrm{P}>0,05)$. $\mathrm{Na}$ safra verão/2001, os frutos apresentaram teores de SST entre 5,5 e $8,7^{\circ}$ Brix. O genótipo 003-APE foi superior aos demais, entretanto, não diferiu dos genótipos 004-RPE e 007-TPA.

Conforme relatado anteriormente, na safra verão/ 2000 , a irrigação, dentre outros fatores, pode ter interferido nos teores SST. Segundo ALVES [13], a chuva ou irrigação excessiva no cultivo da aceroleira, na maioria das vezes, reduz o teor de sólidos solúveis totais do fruto por promover diluição do suco celular. Em acerolas de alguns plantios comerciais, no Nordeste, durante a época das chuvas, o teor de SST atinge aproximadamente $5^{\circ}$ Brix.

TABELA 3. Teor de sólidos solúveis totais (SST) e sua relação com acidez total titulável (SST/ATT) em acerolas maduras do Banco Ativo de Germoplasma, Carpina/PE.

\begin{tabular}{|c|c|c|c|c|c|c|c|c|}
\hline \multirow{3}{*}{$\begin{array}{r}\text { Genótipos } \\
\text { (códigos) }\end{array}$} & \multicolumn{8}{|c|}{ Safras } \\
\hline & \multicolumn{2}{|c|}{ Inverno/1999 } & \multicolumn{2}{|c|}{ Verão/2000 } & \multicolumn{2}{|c|}{ Verão/2001 } & \multicolumn{2}{|c|}{ Média } \\
\hline & $\begin{array}{c}\text { SST } \\
\left({ }^{\circ} \text { Brix }\right)\end{array}$ & SST/ATT & $\begin{array}{c}\text { SST } \\
\left({ }^{\circ} \text { Brix }\right)\end{array}$ & SST/ATT & $\begin{array}{c}\text { SST } \\
\left({ }^{\circ} \text { Brix }\right)\end{array}$ & SST/ATT & $\begin{array}{c}\text { SST } \\
\left({ }^{\circ} \text { Brix) }\right.\end{array}$ & SST/ATT \\
\hline \multirow[t]{2}{*}{ 002-SPE } & 9,3 & 5,5 & 6,3 & 5,4 & 6,8 & 4,7 & 7,5 & 5,2 \\
\hline & $\pm 0,7^{\star a}$ & $\pm 0,3^{\mathrm{abc}}$ & $\pm 0,4^{\mathrm{ab}}$ & $\pm 0,4^{\mathrm{bcd}}$ & $\pm 0,5^{\mathrm{bc}}$ & $\pm 0,2^{\text {bod }}$ & $\pm 0,5^{\mathrm{ab}}$ & $\pm 0,2^{c}$ \\
\hline \multirow[t]{2}{*}{ 003-APE } & 7,7 & 4,9 & 6,7 & 6,8 & 8,7 & 6,0 & 7,7 & 6,2 \\
\hline & $\pm 0,9^{\mathrm{a}}$ & $\pm 0,6^{\mathrm{bc}}$ & $\pm 0,1^{\mathrm{ab}}$ & $\pm 0,2^{a}$ & $\pm 0,9^{\mathrm{a}}$ & $\pm 0,4^{\mathrm{a}}$ & $\pm 0,5^{\mathrm{ab}}$ & $\pm 0,3^{b}$ \\
\hline \multirow[t]{2}{*}{ 004-RPE } & 9,9 & 4,8 & 7,2 & 4,3 & 7,9 & 4,1 & 8,2 & 4,4 \\
\hline & $\pm 1,2^{\mathrm{a}}$ & $\pm 0,3^{\mathrm{bc}}$ & $\pm 0,4^{a}$ & $\pm 0,2^{d}$ & $\pm 0,7^{\mathrm{ab}}$ & $\pm 0,2^{\text {cd }}$ & $\pm 0,5^{\mathrm{ab}}$ & $\pm 0,1^{d}$ \\
\hline \multirow[t]{2}{*}{ 005-APE } & 10,2 & 5,2 & 7,2 & 4,6 & 6,2 & 3,8 & 7,3 & 4,4 \\
\hline & $\pm 0,0^{\mathrm{a}}$ & $\pm 0,2^{\mathrm{bc}}$ & $\pm 0,2^{\mathrm{a}}$ & $\pm 0,2^{\text {cd }}$ & $\pm 0,3^{b c}$ & $\pm 0,1^{d}$ & $\pm 0,4^{\mathrm{ab}}$ & $\pm 0,2^{d}$ \\
\hline \multirow[t]{2}{*}{ 006-TPA } & 10,8 & 6,0 & 7,0 & 6,3 & 6,6 & 4,8 & 7,9 & 5,7 \\
\hline & $\pm 0,8^{\mathrm{a}}$ & $\pm 0,4^{a b c}$ & $\pm 0,2^{\mathrm{a}}$ & $\pm 0,4^{\mathrm{ab}}$ & $\pm 0,2^{b c}$ & $\pm 0,2^{b c}$ & $\pm 0,6^{\mathrm{ab}}$ & $\pm 0,3^{\mathrm{bc}}$ \\
\hline \multirow[t]{2}{*}{ 007-TPA } & 10,6 & 5,5 & 7,3 & 5,7 & 7,8 & 4,8 & 8,4 & 5,3 \\
\hline & $\pm 0,6^{\mathrm{a}}$ & $\pm 0,3^{\mathrm{abc}}$ & $\pm 0,3^{\mathrm{a}}$ & $\pm 0,2^{\mathrm{bc}}$ & $\pm 0,2^{\mathrm{ab}}$ & $\pm 0,2^{\mathrm{bc}}$ & $\pm 0,5^{\mathrm{a}}$ & $\pm 0,2^{c}$ \\
\hline \multirow[t]{2}{*}{ 008-СРA } & 9,0 & 4,4 & 6,2 & 5,0 & 6,5 & 4,8 & 7,0 & 4,8 \\
\hline & $\pm 1,3^{\mathrm{a}}$ & $\pm 0,5^{c}$ & $\pm 0,1^{a b}$ & $\pm 0,3^{\text {cd }}$ & $\pm 0,6^{b c}$ & $\pm 0,1^{\text {bod }}$ & $\pm 0,5^{b}$ & $\pm 0,2^{d}$ \\
\hline \multirow[t]{2}{*}{ 011-BPA } & 10,0 & 5,8 & 6,3 & 6,0 & 5,5 & 4,7 & 7,1 & 5,4 \\
\hline & $\pm 0,9^{a}$ & $\pm 0,2^{\mathrm{abc}}$ & $\pm 0,2^{\mathrm{ab}}$ & $\pm 0,2^{\mathrm{bc}}$ & $\pm 0,2^{c}$ & $\pm 0,3^{\mathrm{bcd}}$ & $\pm 0,6^{\mathrm{b}}$ & $\pm 0,2^{c}$ \\
\hline \multirow[t]{2}{*}{ 012-CPA } & 10,3 & 6,8 & 6,5 & 5,1 & 7,0 & 5,2 & 8,0 & 5,7 \\
\hline & $\pm 0,4^{\mathrm{a}}$ & $\pm 0,4^{\mathrm{ab}}$ & $\pm 0,2^{\mathrm{ab}}$ & $\pm 0,2^{\mathrm{bcd}}$ & $\pm 0,4^{b c}$ & $\pm 0,3^{b}$ & $\pm 0,5^{\mathrm{ab}}$ & $\pm 0,3^{b c}$ \\
\hline \multirow[t]{2}{*}{ 013-СРА } & 9,8 & 5,1 & 6,2 & 4,7 & 6,1 & 4,2 & 7,5 & 4,7 \\
\hline & $\pm 0,2^{a}$ & $\pm 0,1^{\mathrm{bc}}$ & $\pm 0,2^{\mathrm{ab}}$ & $\pm 0,2^{c d}$ & $\pm 0,4^{\mathrm{bc}}$ & $\pm 0,1^{\mathrm{bod}}$ & $\pm 0,5^{\mathrm{ab}}$ & $\pm 0,1^{d}$ \\
\hline \multirow[t]{2}{*}{ 014-СРА } & 10,0 & 6,9 & 6,5 & 5,4 & 5,9 & 4,7 & 7,3 & 5,6 \\
\hline & $\pm 0,4^{a}$ & $\pm 0,5^{\mathrm{ab}}$ & $\pm 0,2^{\mathrm{ab}}$ & $\pm 0,2^{\mathrm{bcd}}$ & $\pm 0,5^{c}$ & $\pm 0,2^{\mathrm{bcd}}$ & $\pm 0,5^{\mathrm{ab}}$ & $\pm 0,3^{c}$ \\
\hline \multirow[t]{2}{*}{ 015-CPA } & 9,4 & 7,3 & 5,8 & 7,0 & 6,5 & 6,4 & 7,1 & 6,9 \\
\hline & $\pm 0,8^{a}$ & $\pm 0,6^{a}$ & $\pm 0,1^{\mathrm{b}}$ & $\pm 0,6^{a}$ & $\pm 0,3^{\mathrm{bc}}$ & $\pm 0,4^{\mathrm{a}}$ & $\pm 0,5^{b}$ & $\pm 0,3^{\mathrm{a}}$ \\
\hline Média & 9,8 & 5,8 & 6,6 & 5,5 & 6,8 & 4,9 & 7,6 & 5,4 \\
\hline L. sup. ${ }^{1}$ & 10,3 & 6,4 & 6,9 & 6,0 & 7,4 & 5,3 & 7,9 & 5,8 \\
\hline L. inf. ${ }^{1}$ & 9,4 & 5,2 & 6,3 & 5,0 & 6,2 & 4,4 & 7,3 & 4,9 \\
\hline C.V. $(\%)^{2}$ & 15,2 & 13,6 & 7,8 & 12,3 & 13,1 & 10,2 & 16,9 & 10,6 \\
\hline
\end{tabular}

Na análise conjunta das safras foi evidenciado que, para a maioria dos genótipos, os valores de SST encontravam-se na faixa de 7,0 a $7,5^{\circ}$ Brix, o que é desejável para as indústrias [16]. Estes níveis estão de acordo com os relatados por ALVES [3], para as condições climáticas brasileiras. Genótipos de acerola, cultivados em Petrolina/PE, sob irrigação, apresentaram teores de SST entre 4,7 a $9,2^{\circ}$ Brix [13]. SEMENSATO \& PEREIRA [24] observaram variações médias de 5,40 a $8,27^{\circ}$ Brix em 9 genótipos de aceroleiras cultivados sob elevada altitude (Município de Anápolis, GO).

\section{4 - Relação SST/ATT}

A relação SST/ATT está diretamente relacionada à qualidade dos frutos quanto ao atributo sabor. Na Tabela 3, observa-se que os valores de SST/ATT dos frutos das safras apresentaram diferença estatística significativa $(\mathrm{P}<0,05)$ entre os genótipos. A análise conjunta dos dados (médias das safras) destaca o genótipo 015-CPA como o menos ácido. SANTOS et al. [23] também encontraram, em acerolas maduras, diferença significativa na relação SST/ATT.

\section{$3.5-$ pH}

Em acerolas, inclusive nas maduras, o pH é um parâmetro que apresenta baixa variabilidade. Fato confirmado neste estudo, tendo em vista que, dentre as características físico-químicas analisadas, esta variável apresentou o menor coeficiente de variação (Tabela 4).

A análise conjunta das safras evidenciou uma variação média de 3,11 a 3,41, valores que se encontram próximos aos citados por BATISTA, MUGÜET \& BELTRÃO [5]; ALVES [2]; BATISTA, FIGUEIREDO \& QUEIROZ [6]. Em todas as safras, observa-se uma indicação de associação fenotípica do $\mathrm{pH}$ com a relação SST/ATT, e com a acidez e o ácido ascórbico (Tabelas 1, 2, 3 e 4).

TABELA 4. Determinação de $\mathrm{pH}$ em acerolas maduras do Banco Ativo de Germoplasma, Carpina/PE.

\begin{tabular}{|c|c|c|c|c|}
\hline \multirow{2}{*}{$\begin{array}{l}\text { Genótipos } \\
\text { (códigos) }\end{array}$} & \multicolumn{4}{|c|}{ Safras } \\
\hline & Inverno/1999 & Verão/2000 & Verão/2001 & Média \\
\hline 002-SPE & $3,20 \pm 0,03^{* b}$ & $3,28 \pm 0,02^{b c}$ & $3,05 \pm 0,10^{a b}$ & $3,19 \pm 0,06^{b}$ \\
\hline 003-APE & $3,10 \pm 0,10^{b}$ & $3,40 \pm 0,05^{a b}$ & $3,14 \pm 0,10^{a b}$ & $3,24 \pm 0,06^{b}$ \\
\hline 004-RPE & $3,18 \pm 0,09^{b}$ & $3,26 \pm 0,02^{b c}$ & $2,90 \pm 0,06^{a b}$ & $3,11 \pm 0,05^{b}$ \\
\hline 005-APE & $3,20 \pm 0,10^{b}$ & $3,20 \pm 0,04^{c}$ & $3,02 \pm 0,08^{a b}$ & $3,13 \pm 0,05^{b}$ \\
\hline 006-TPA & $3,20 \pm 0,04^{b}$ & $3,32 \pm 0,02^{a b c}$ & $3,14 \pm 0,07^{\mathrm{ab}}$ & $3,22 \pm 0,03^{b}$ \\
\hline 007-TPA & $3,23 \pm 0,06^{b}$ & $3,38 \pm 0,05^{a b c}$ & $2,84 \pm 0,09^{b}$ & $3,14 \pm 0,07^{b}$ \\
\hline 008-СРА & $3,10 \pm 0,06^{b}$ & $3,20 \pm 0,05^{c}$ & $3,05 \pm 0,06^{a b}$ & $3,13 \pm 0,04^{b}$ \\
\hline 011-BPA & $3,25 \pm 0,03^{b}$ & $3,40 \pm 0,06^{a b}$ & $3,18 \pm 0,05^{a b}$ & $3,28 \pm 0,04^{b}$ \\
\hline 012-CPA & $3,28 \pm 0,02^{b}$ & $3,20 \pm 0,01^{c}$ & $2,98 \pm 0,12^{a b}$ & $3,15 \pm 0,05^{b}$ \\
\hline 013-СРА & $3,20 \pm 0,03^{b}$ & $3,38 \pm 0,04^{a b c}$ & $3,08 \pm 0,03^{a b}$ & $3,23 \pm 0,04^{b}$ \\
\hline 014-СРА & $3,25 \pm 0,03^{b}$ & $3,28 \pm 0,02^{b c}$ & $3,10 \pm 0,10^{a b}$ & $3,21 \pm 0,04^{b}$ \\
\hline 015-СРА & $3,45 \pm 0,03^{a}$ & $3,46 \pm 0,02^{a}$ & $3,32 \pm 0,10^{a}$ & $3,41 \pm 0,04^{a}$ \\
\hline Média & 3,23 & 3,31 & 3,07 & 3,20 \\
\hline L. sup. ${ }^{1}$ & 3,28 & 3,37 & 3,15 & 3,26 \\
\hline L. inf. ${ }^{1}$ & 3,18 & 3,26 & 2,98 & 3,15 \\
\hline C.V. $(\%)^{2}$ & 2,79 & 2,64 & 6,56 & 4,53 \\
\hline
\end{tabular}

* Médias seguidas da mesma letra na coluna não diferem significativamente ao nível de $5 \%$ de probabilidade pelo teste de Student-Newman-Keuls (SNK).

Intervalo de confiança da média com 95\% de probabilidade, limites superior e nferior.

\section{6 - Antocianinas e flavonóis}

Os teores de antocianinas totais nos frutos das três safras variaram estatisticamente $(\mathrm{P}<0,05)$ entre os genótipos (Tabela 5). Uma maior amplitude de variação 
nos teores destes constituintes foi observada nas safras inverno/1999 e verão/2000, cujos valores encontram-se na faixa de 4,1 a $55,8 \mathrm{mg} / 100 \mathrm{~g}$ de polpa, enquanto que, na safra verão/2001 esta amplitude foi menor $(2,4$ a $39,9 \mathrm{mg} / 100 \mathrm{~g}$ de polpa). PAIVA et al. [22] também encontraram uma grande variação no teor de antocianinas em acerolas (1,97 a 46,44mg/100g) instaladas no Campo Experimental de Pacajus, pertencente a EMBRAPA Agroindústria Tropical. O genótipo 005-APE, com polpa de cor vermelha escura apresentou, em todas as safras, o maior teor deste fitoquímico $(\mathrm{P}<0,05)$.

TABELA 5. Teor de antocianinas totais (mg/loog de polpa) em acerolas maduras do Banco Ativo de Germoplasma, Carpina/PE.

\begin{tabular}{|c|c|c|c|c|}
\hline \multirow{2}{*}{$\begin{array}{l}\text { Genótipos } \\
\text { (códigos) }\end{array}$} & \multicolumn{4}{|c|}{ Safras } \\
\hline & Inverno/1999 & Verão/2000 & Verão/2001 & Média \\
\hline 002-SPE & $4,1 \pm 1,4^{\star d}$ & $4,6 \pm 0,5^{9}$ & $2,4 \pm 0,9^{e}$ & $3,8 \pm 0,6^{n}$ \\
\hline 003-APE & $9,4 \pm 2,0^{d}$ & $8,8 \pm 1,0^{e g}$ & $12,4 \pm 0,9^{d}$ & $10,4 \pm 0,8^{\mathrm{fg}}$ \\
\hline 004-RPE & $18,9 \pm 7,4^{c d}$ & $19,1 \pm 1,1^{\text {cd }}$ & $25,1 \pm 2,1^{b c}$ & $21,2 \pm 2,2^{d}$ \\
\hline 005-APE & $55,8 \pm 5,0^{a}$ & $51,5 \pm 4,9^{\mathrm{a}}$ & $39,9 \pm 3,5^{\mathrm{a}}$ & $47,4 \pm 3,1^{a}$ \\
\hline 006-TPA & $15,9 \pm 1,7^{d}$ & $24,4 \pm 0,7^{\text {bcd }}$ & $13,4 \pm 1,4^{d}$ & $18,1 \pm 1,5^{\mathrm{de}}$ \\
\hline 007-TPA & $29,1 \pm 2,9^{c}$ & $26,1 \pm 4,7^{\text {bcd }}$ & $22,3 \pm 2,7^{c}$ & $25,6 \pm 2,1^{c}$ \\
\hline 008-CPA & $28,3 \pm 7,5^{c}$ & $30,2 \pm 2,7^{b}$ & $28,0 \pm 2,2^{b c}$ & $29,0 \pm 2,0^{c}$ \\
\hline 011-BPA & $45,9 \pm 4,5^{b}$ & $28,8 \pm 2,0^{b c}$ & $29,9 \pm 2,9^{b}$ & $34,1 \pm 2,6^{b}$ \\
\hline 012-CPA & $10,2 \pm 3,2^{d}$ & $16,3 \pm 2,0^{\text {def }}$ & $10,4 \pm 0,7^{d}$ & $12,3 \pm 1,4^{\mathrm{fg}}$ \\
\hline 013-CPA & $13,8 \pm 2,4^{d}$ & $19,2 \pm 3,9^{c d}$ & $8,4 \pm 1,2^{\mathrm{de}}$ & $14,2 \pm 2,0^{\text {ef }}$ \\
\hline 014-CPA & $8,3 \pm 1,6^{d}$ & $17,3 \pm 1,5^{\text {de }}$ & $9,7 \pm 1,2^{\mathrm{de}}$ & $12,0 \pm 1,3^{\mathrm{fg}}$ \\
\hline 015-СРА & $10,2 \pm 1,8^{d}$ & $7,1 \pm 0,1^{g}$ & $5,8 \pm 0,5^{d e}$ & $7,5 \pm 0,7^{\text {gh }}$ \\
\hline Média & 18,9 & 21,1 & 17,5 & 19,2 \\
\hline L. sup. ${ }^{1}$ & 27,8 & 29,2 & 24,8 & 27,0 \\
\hline L. inf. ${ }^{1}$ & 10,0 & 13,1 & 10,3 & 11,5 \\
\hline C.V. $(\%)^{2}$ & 33,8 & 26,8 & 24,2 & 27,6 \\
\hline
\end{tabular}

Os teores de flavonóis totais dos frutos das safras estudadas variaram de 5,9 a 22,2mg de quercetina/ $100 \mathrm{~g}$ de polpa (Tabela 6). Os dados demonstram que os frutos dos genótipos 005-APE e 011-BPA, na safra inverno/1999, apresentaram os maiores teores deste fitoquímico. Na safra verão/2000, apenas os frutos do genótipo 005-APE apresentaram teor deste constituinte superior estatisticamente. No entanto, na safra verão/2001, além deste genótipo, destacou-se o 008-CPA, ambos não diferindo estatisticamente dos genótipos 004-RPE e 011-BPA. A análise conjunta das safras demonstra que os genótipos 005-APE e 011-BPA apresentaram os mais altos teores de flavonóis totais.

Em todos os genótipos, com exceção do 002-SPE e 015-CPA, os teores de antocianinas totais foram mais elevados do que os de flavonóis totais. VENDRAMINI \& TRUGO [26] também verificaram que os valores de antocianinas totais $(14,9$ e $12,41 \mathrm{mg} / 100 \mathrm{~g})$ foram maiores do que os de flavonóis (11,02 e 8,82mg/100g) em cascas de acerolas das variedades "Flor Branca" e "Okinawa", provenientes do Rio Grande do Norte, respectivamente.
TABELA 6. Teor de flavonóis totais (mg de quercetina/100g de polpa) em acerolas maduras do Banco Ativo de Germoplasma, Carpina/PE

\begin{tabular}{lcccc}
\hline Genótipos & \multicolumn{3}{c}{ Safras } \\
\cline { 2 - 5 } (códigos) & Inverno/1999 Verão/2000 & Verão/2001 & Média \\
\hline 002-SPE & $8,2 \pm 0,8^{*^{\mathrm{b}}}$ & $6,7 \pm 0,3^{\mathrm{d}}$ & $5,9 \pm 0,8^{\mathrm{d}}$ & $7,0 \pm 0,4^{\mathrm{d}}$ \\
003-APE & $6,9 \pm 0,3^{\mathrm{b}}$ & $6,9 \pm 0,4^{\mathrm{d}}$ & $7,1 \pm 0,4^{\mathrm{cd}}$ & $7,0 \pm 0,2^{\mathrm{d}}$ \\
004-RPE & $13,1 \pm 3,5^{\mathrm{b}}$ & $10,9 \pm 0,4^{\mathrm{c}}$ & $14,6 \pm 0,5^{\mathrm{ab}}$ & $12,8 \pm 1,0^{\mathrm{c}}$ \\
005-APE & $21,2 \pm 0,1^{\mathrm{a}}$ & $18,3 \pm 1,6^{\mathrm{a}}$ & $17,5 \pm 1,1^{\mathrm{a}}$ & $18,5 \pm 0,8^{\mathrm{a}}$ \\
006-TPA & $10,3 \pm 0,7^{\mathrm{b}}$ & $11,8 \pm 0,3^{\mathrm{bc}}$ & $9,9 \pm 0,8^{\mathrm{c}}$ & $10,7 \pm 0,4^{\mathrm{c}}$ \\
007-TPA & $12,4 \pm 1,1^{\mathrm{b}}$ & $13,0 \pm 1,1^{\mathrm{bc}}$ & $13,8 \pm 1,3^{\mathrm{b}}$ & $13,1 \pm 0,6^{\mathrm{c}}$ \\
008-CPA & $14,1 \pm 2,9^{\mathrm{b}}$ & $13,5 \pm 1,3^{\mathrm{bc}}$ & $17,3 \pm 1,0^{\mathrm{a}}$ & $14,9 \pm 1,0^{\mathrm{b}}$ \\
011-BPA & $22,2 \pm 2,3^{\mathrm{a}}$ & $14,7 \pm 0,6^{\mathrm{b}}$ & $15,0 \pm 0,6^{\mathrm{ab}}$ & $17,0 \pm 1,1^{\mathrm{a}}$ \\
012-CPA & $11,0 \pm 2,1^{\mathrm{b}}$ & $11,7 \pm 0,4^{\mathrm{bc}}$ & $10,3 \pm 0,2^{\mathrm{c}}$ & $11,0 \pm 0,7^{\mathrm{c}}$ \\
013-CPA & $13,7 \pm 1,5^{\mathrm{b}}$ & $12,9 \pm 1,3^{\mathrm{bc}}$ & $9,7 \pm 1,4^{\mathrm{c}}$ & $12,3 \pm 0,9^{\mathrm{c}}$ \\
014-CPA & $10,2 \pm 1,2^{\mathrm{b}}$ & $12,5 \pm 0,8^{\mathrm{bc}}$ & $9,1 \pm 0,7^{\mathrm{c}}$ & $10,6 \pm 0,6^{\mathrm{c}}$ \\
015-CPA & $9,4 \pm 0,8^{\mathrm{b}}$ & $6,9 \pm 0,2^{\mathrm{d}}$ & $7,1 \pm 0,7^{\mathrm{cd}}$ & $7,7 \pm 0,4^{\mathrm{d}}$ \\
\hline Média & 12,5 & 11,6 & 11,5 & 11,8 \\
L. sup. $^{1}$ & 15,1 & 13,8 & 14,0 & 14,1 \\
L. inf. $^{1}$ & 9,8 & 9,5 & 8,9 & 9,5 \\
C.V.(\%) $^{2}$ & 25,3 & 15,8 & 15,5 & 18,8 \\
\hline
\end{tabular}

* Médias seguidas da mesma letra na coluna não diferem significativamente ao nível de 5\% de probabilidade pelo teste de Student-Newman-Keuls (SNK).

${ }^{1}$ Intervalo de confiança da média com 95\% de probabilidade, limites superior e

${ }_{2}^{\text {inferior. }}$ Coeficiente de variação.

A análise estatística dos dados revelou um indicativo de forte associação fenotípica entre flavonóis e antocianinas, evidenciada pelos mesmos limites do intervalo de confiança da média e da significância $(\mathrm{P}<0,05)$ e, visualizada principalmente na análise conjunta das safras. Segundo HARBORNE [14], os flavonóis sempre acompanham as antocianinas em frutos, provavelmente porque apresentam caminhos de biossíntese semelhantes.

\section{4 - CONCLUSÕES}

As condições meteorológicas influenciaram de forma marcante nas características físico-químicas dos frutos. Em todos os genótipos, exceto 015-CPA, os níveis de ácido ascórbico encontravam-se acima do padrão mínimo, e os teores de SST, para a maioria dos genótipos, dentro da faixa desejável pelas indústrias de transformação. Com base nas variáveis analisadas, todos os genótipos, exceto o 015-CPA, são potencialmente promissores.

\section{5 - REFERÊNCIAS BIBLIOGRÁFICAS}

[1] ALVES, R.E. Acerola (Malpighia emarginata D.C.) fisiologia da maturação e armazenamento refrigerado sob atmosfera ambiente e modificada, Lavras, 1993, 99p. (Mestrado). Departamento de Ciência dos Alimentos, Universidade Federal de Lavras.

[2] ALVES, R.E. Cultura da acerola. In: Donadio LC, Martins ABG, Valente JP, editores. Fruticultura tropical. Jaboticabal: FUNEP. p. 15-37, 1992.

[3] ALVES, R.E. Características das frutas para exportação. In: Gorgatti Netto A, Ardito EFG, Garcia EEC, Bleinroth 
EW, Freire FCO, Menezes JB, Bordin MR, Braga Sobrinho R, Alves RE, editores. Acerola para exportação: procedimentos de colheita e pós-colheita. Brasília: EMBRAPA-SPI (Série Publicações Técnicas FRUPEX, 21), p. 09-12, 1996.

[4] AOAC - Association of Official Analytical Chemists. Official Methods of Analysis of the Association of Official Analytical Chemists. $15^{\text {th }}$ ed., Arlington: AOAC, v. 2, 1990.

[5] BATISTA, F.A.S.; MUGÜET, B.R.R.; BELTRÃO, A.E.S. Comportamento e seleção da aceroleira na Paraíba. Anais do X Congresso Brasileiro de Fruticultura, p. 26-32, 1991.

[6] BATISTA, M.S.; FIGUEIRÊDO, R.M.F.; QUEIROZ, A.J.M. Caracterização físico-química de acerola (Malpighia punicifolia L.) em três estádios de maturação. Anais do XVII Congresso Brasileiro de Ciência e Tecnologia de Alimentos, v. 2, p. 5108, 2000.

[7] BEZERRA NETO, E.; ANDRADE, A.G.; BARRETO, L.P. Análise química de tecidos e produtos vegetais. Recife: UFRPE, 99p., 1994.

[8] CARPENTIERI-PÍPOLO, V.; PRETE, C.E.C.; GONZALES, M.G.N.; POPPER, I.O. Novas cultivares de acerola (Malpighia emarginata DC): UEL 3 - Dominga, UEL 4 Lígia e UEL 5 - Natália. Rev. Bras. Frutic., v. 24, n. 1, p. 124-126, 2000.

[9] CATI. CATI lança nova acerola cultivar - Waldy CATI 30. São Paulo: Governo do Estado de São Paulo, 1997.

[10] CONCEIÇÃO, M.P.J. Cinética da degradação térmica de antocianinas em suco de acerola (Malpighia glabra L.), Viçosa, 1997, 59p. (Mestrado). Departamento Ciência e Tecnologia de Alimentos, Universidade Federal de Viçosa.

[11] DONADIO, L.C. Novas variedades brasileiras de frutas. Jaboticabal: SBF, 205p., 2000.

[12] GOMES, J.E.; PERECIN, D.; MARTINS, A.B.G.; FONTES, S. Variações físico-químicas em suco de acerola armazenado. Rev. Bras. Frutic., v. 22, n. 3, p. 377-381, 2000.

[13] GONZAGA NeTO, L.; MATTUZ, B.H.; SANTOS, C.A.F. Caracterização agronômica de clones de aceroleira (Malpighia spp) na Região do Submédio São Francisco. Rev. Bras. Frutic., v. 21, n. 2, p. 110-115, 1999.

[14] HARBORNE, J.B. Comparative biochemistry of the flavonoids. London: Academic Press., 1967, 383p.

[15] INSTITUTO ADOLFO LUTZ. Normas Analíticas do Instituto Adolfo Lutz - métodos químicos e físicos para análise de alimentos, v.1, $2^{\text {a }}$ ed., São Paulo: Instituto Adolfo Lutz, p. 138-150, 1973.

[16] INSTITUTO BRASILEIRO DE FRUTAS. Soluções fruta a fruta: acerola. $2^{a}$ ed São Paulo: IBRAF, 1995, 64p.

[17] LEES, D.H.; FRANCIS, F.J. Standardization of pigment analyses in cranberries. Hort. Sci., v. 7, n. 1, p. 83-84, 1972.

[18] LIMA, V.L.A.G.; MÉLO, E.A.; LIMA, L.S.; NASCIMENTO, P.P. Flavonóides em seleções de acerola (Malpighia sp): 1- Teor de antocianinas e flavonóis totais. Ciência Rural, v. 30, n. 6, p. 1063-1064, 2000.

[19] MATSUURA, F.C.A.U.; CARDOSO, R.L.; FOLEGATTI, M.I.S.; OLIVEIRA, J.R.P.; OLIVEIRA, J.A.B.; SANTOS, D.B. Avaliações físico-químicas em frutos de diferentes genótipos de acerola (Malpighia punicifolia L.). Rev. Bras. Frutic., v. 23, n. 3, p. 602-606, 2001.

[20] NOGUEIRA, R.J.M.C.; MORAES, J.A.P.V.; BURITY, H.A.; SILVA JUNIOR, J.F. Efeito do estádio de maturação dos frutos nas características físico-químicas de acerola. Pesq. Agropec. Bras., v. 37, n. 4, p. 463-470, 2002.

[21] OLIVEIRA, J.R.P.; SOARES FILHO, W.S.; NASCIMENTO, A.S.; COSTA, D.C.; MATSUURA, F.C.A.U; GOMES, J.C.; CARVALHO, J.E.B.; REINHARDT, D.H.; OLIVEIRA, R.P. Programa de pesquisa de acerola. Cruz das Almas: EMBRAPA-CNPMF (Documentos, 75). 1998, 28p.

[22] PAIVA, J.R.; CORDEIRO, E.R.; ALVES, R.E.; ALMEIDA, A.S.; PINTO, S.A.A. Seleção e clonagem de plantas de acerola. Anais do XIV Encontro de Genética do Nordeste, 1999, p. 53.

[23] SANTOS, A.R.L.; REINHARDT, D.H.; SILVEIRA, W.R.; OLIVEIRA, J.R.P.; CALDAS, R.C. Qualidade pós-colheita de acerola para processamento em função de estádios de maturação e condições de armazenamento. Rev. Bras. Frutic., v. 21, n. 3, p. 365-371, 1999

[24] SEMENSATO, L.R.; PEREIRA, A.S. Características de frutos de genótipos de aceroleira cultivados sob elevada altitude. Pesq. Agropec. Bras., v. 35, n. 12, p. 25292536, 2000.

[25] VENDRAMINI, A.L.; TRUGO, L.C. Chemical composition of acerola fruit (Malpighia punicifolia L.) at three stages of maturity. Food Chem., v. 71, p. 195-198, 2000a.

[26] VENDRAMINI, A.L.; TRUGO, L.C. Fracionamento e identificação de compostos fenólicos da acerola (Malpighia punicifolia L.). Anais do XVII Congresso Brasileiro de Ciência e Tecnologia de Alimentos, v. 2, p. 5217 , 2000b. 